\title{
Madame Bovary, c'est moi
}

\section{Once upon a time, fiction required the suspension of disbelief.}

\section{Dan Simmons}

2 052 AD: the current migration of millions of people to novel universes by quantum teleportation (QT) was a shock even to the system's inventor, JianWei Martini. "I don't know why it took me by surprise," said Dr Martini in a 2043 interview. "I had the basic idea for QT when I read an ancient New Yorker story by Woody Allen, but the potential was all there in Schrödinger's classic wave equation.” Dr Martini has since QT'd to Madame Bovary's universe and is currently living in Flaubert's Paris as Monsieur Leon.

The quantum-mechanical entanglement effect had been analysed (in Einstein's sceptical term) as "spooky action at a distance" since 1935, but it was not until 1998 that a research group at the University of Innsbrück demonstrated actual quantum teleportation of a photon - or more precisely, the complete quantum state of that photon.

These initial quantum-state teleportations avoided violating Heisenberg's principle and Einstein's speed-of-light restrictions because teleported photons carried no information, even about their own quantum state. However, by producing entangled pairs of photons and teleporting one of the pair while transmitting the Bell-state analysis of the second photon through subluminal channels, the recipient of the teleported photon-data had a one-in-four chance of guessing its quantum state and then utilizing the quantum bits of teleported data.

All of this would have amounted to very little except for remarkable advances in human-consciousness research. Researchers at the University of Kiev interested in improving memory function used quantum computers to analyse biochemical cascades in human synapses. In 2025, they discovered that the human mind - as opposed to the brain - was neither like a computer nor a chemical memory machine, but exactly like a quantum-state holistic standing wavefront.

The human brain, it turned out, collapsed probability functions of this standing wavefront of consciousness in the same way that an interferometer determined the quantum state of a photon or any other wavefront phenomenon. Using terabytes of qubit quantum data and applying relativistic Coulomb field transforms to these mindconsciousness holographic wavefunctions, it was quickly discovered that human consciousness could be quantum-teleported to points in space-time where entangled-pair

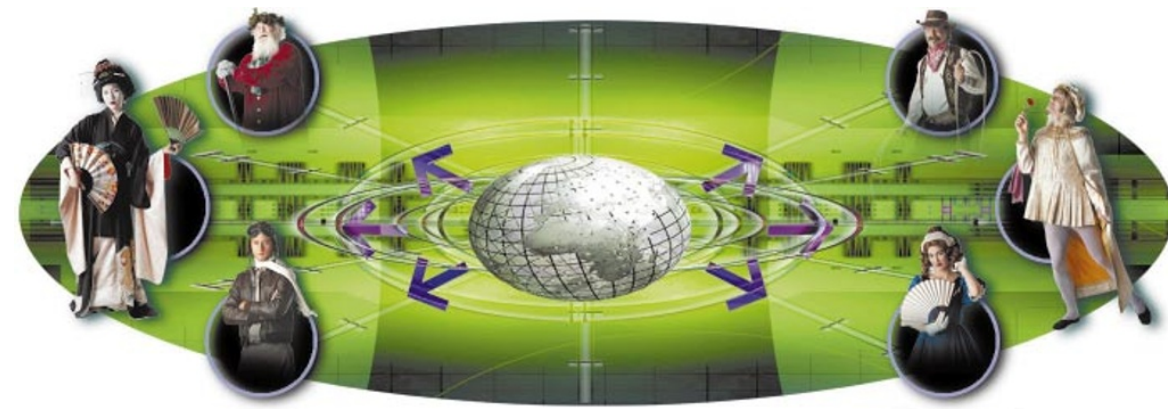

wavefronts already existed.

And where were these places? Nothing as complex as an entangled consciousnesswavefront existed elsewhere in our continuum. QT researchers soon realized that they were teleporting human consciousness or, rather, the complete quantum state of these consciousnesses - to alternate universes that had, in turn, come into being through the focus of pre-existing holographic wavefronts: in other words, complete alternate universes created by the sheer force of human imagination. These singularities of genius act as Bell-state analyser/editors on the quantum-foam of reality, simultaneously interpreting one universe while creating a new one.

It seems that poets, playwrights and novelists already understood this. "The imagination may be compared to Adam's dream," wrote John Keats: "he awoke and found it truth."

The QT charting of 'fiction universes' began immediately, but even before a hundred alternate universes were confirmed, the QT migration from our Earth began.

Meanwhile, the 'agon' - the imperative to rank the relative importance of creative works - now had a scientific tool at its disposal. The long literary debate as to which works belonged in the so-called 'Western Canon' was settled by QT exploration. For example, 21 of Shakespeare's 38 plays generated complete alternate universes, as complex and expansive as our own, each capable of supporting a human population from a few thousand (Measure for Measure) to many billions (King Lear), despite the fact that each play may have had a cast of a score or fewer players when it was performed. More than a million people have migrated to Elsinore, whereas fewer than 5,000 — mostly clinically depressed Scandinavians - have seen fit to re-establish themselves in Lear's universe.

Flaubert, it turned out, generated two complete universes - the so-called "Madame Bovary's World" and that of Senti- mental Education — whereas Alice Walker, it seems, to the frustration of American academics, had created none.

The alternate universe of Dante's Inferno has received more than 385,000 emigrants (mostly from Southern California), but his Paradiso Planet shows only 649 transplants. The current count of those who have QT'd to Huckleberry Finn's "River World" is $3,622,406$, and more than a million have been transported to each of Charles Dickens's five extant universes.

It is true that more than 60 million people volunteered to QT to D. H. Lawrence's "Lady Chatterley's World", but — sadly — no such discrete universe has been found. Some have made do with the universe of Sons and Lovers. Recent QT stampedes to the worlds of Jane Austen, Robert Louis Stevenson and the effectively infinite number of universes created by Jorge Luis Borges may reflect current social trends.

It remains to be seen whether QT technology will solve the current global population crisis or if it will remain an option of the rich, bored and educated. It also remains to be seen whether any universes will be found - beyond the paltry handful already discovered - that owe their origins to 21 st-century imaginations.

"That which is creative must create itself," said John Keats. And perhaps more pointedly, from William Blake - "I must create a system or be enslaved by another man's."

Which brings us to the central question of this new quantum reality. None of the millions of ancillary characters living in Madame Bovary's universe (except for the QT emigrés) know that they are characters in a work of fiction. Nor do they know that Madame Bovary is the main character.

So who wrote our universe? And who are the central characters?

Dan Simmons is the author of 16 books, four or five of which have been science fiction. His most recent novel is Darwin's Blade (published in October 2000 by William Morrow/HarperCollins). 